\section{Ganglion cell complex thickness in nonexudative age- related macular degeneration}

E Yenice, A Şengün, G Soyugelen Demirok and E Turaçlı
Dr Rıdvan Ege Hospital, Faculty of Medicine, Ufuk University, Ankara, Turkey

Correspondence:

E Yenice, Konutkent 2 Site B6 Block Number 20/1, Çayyolu, Ankara, Turkey Tel: +90 312204 4000; Fax: +90 3122041212 E-mail: esay_kiran@hotmail. com

Received: 25 September 2014

Accepted in revised form: 14 April 2015

Published online:

29 May 2015

\begin{abstract}
Purpose To evaluate ganglion cell complex (GCC) thickness with spectral domain optical coherence tomography (SD-OCT) in eyes with nonexudative age-related macular degeneration (NEAMD).

Methods Forty-seven eyes of 28 patients with nonexudative age-related macular degeneration (NEAMD) and 54 eyes of 28 age-matched healthy subjects were enrolled. Each subject underwent a complete ophthalmic examination before SD-OCT were obtained. Macular scans were taken with software version 6.0 of the ganglion cell analysis (GCA) algorithm. GCC thickness was evaluated automatically as the average, minimum, temporal superior, superior, nasal superior, nasal inferior, inferior, and temporal-inferior segments by SD-OCT and parameters were compared between groups. Results The mean age was $68.7 \pm 8.73$ years in patient group, and $61.51 \pm 5.66$ years in control group. There were no significant differences in mean age, gender distribution, intraocular pressure, and sferic equivalent at imaging between the groups $(P>0.05)$. The mean $( \pm$ SD) GCC thicknesses were as follows; average $71.53 \pm 16.53 \mu \mathrm{m}$, minumum $62.36 \pm 21.51 \mu \mathrm{m}$, temporal superior $72.23 \pm 14.60 \mu \mathrm{m}$, superior $72.76 \pm 20.40 \mu \mathrm{m}$, nasal superior $72.31 \pm 20.13 \mu \mathrm{m}$, nasal inferior $69.74 \pm 20.51 \mu \mathrm{m}$, inferior $69.38 \pm 19.03 \mu \mathrm{m}$, and temporal-inferior $73.12 \pm 15.44 \mu \mathrm{m}$ in patient group. Corresponding values in control group were $81.46 \pm 4.90 \mu \mathrm{m}, 78.66 \pm 6.00 \mu \mathrm{m}$, $81.51 \pm 4.66 \mu \mathrm{m}, 82.94 \pm 5.14 \mu \mathrm{m}$, $81.79 \pm 5.86 \mu \mathrm{m}, 80.94 \pm 6.18 \mu \mathrm{m}$, $80.14 \pm 6.30 \mu \mathrm{m}$, and $81.75 \pm 5.26 \mu \mathrm{m}$, respectively. There were significant differences between two groups in each segments (Mann-Whitney $U$-test, $P<0.05$ ). Conclusion The average GCC thickness values (in all segments) of NEAMD patients
\end{abstract} which is considered as a disease of oute layers of retina, may be accompanied with a decrease of ganglion cell thickness, so inner layers of retina may be affected.

Eye (2015) 29, 1076-1080; doi:10.1038/eye.2015.86; published online 29 May 2015

Introduction

Age-related macular degeneration (AMD) is one of the leading causes of irreversible vision loss and blindness among elderly persons. ${ }^{1,2}$ AMD involving Bruch membrane, retinal pigment epithelium, and choriocapillaris, is a degenerative and progressive disease. The classification systems have been developed to characterize disease severity; Nonexudative AMD that is called dry or atrophic AMD, and exudative AMD that is called wet or exudative AMD. 2,3 Drusen, acellular deposits of lipids, proteins, and inflammatory mediators, are common both early and late stages of disease.

NEAMD is characterized by gradual vision loss associated with retinal pigmentary change, drusen, and the development of geographic atrophy of the retina pigment epithelium (RPE). ${ }^{3-5}$

The exudative form of AMD (EAMD) is responsible for rapid and severe vision loss due to the development of choroidal neovascularization (CNV). ${ }^{3-5}$ Recently, optical coherence tomography of AMD has found an important place in the diagnosis and follow-up of the disease.

The Cirrus OCT (Carl Zeiss Meditec, Inc., Dublin, CA, USA), two-dimensional crosssectional retinal images consisting of 512 A-lines with axial resolutions of $10 \mathrm{~mm}$ can be obtained in $1.28 \mathrm{~s} .{ }^{4}$ A-scans per second, pupil dilation is necessary for optimal measurement also ganglion cell complex (GCC) and other retinal 
layer thickness. Spectral domain optical coherence tomography (SD-OCT) can better evaluate drusen and associated anatomical changes in eyes with NEAMD. ${ }^{6}$

The GCC thickness comprises the retinal ganglion cell layer (GCL) and inner plexiform layer (IPL), which are directly influenced by several potentially blinding eye diseases, such as glaucoma, retinitis pigmentosa (RP). ${ }^{4-9}$

Medeiros et $a l^{4}$ demonstrate diffuse loss of photoreceptor cells in NEAMD in histopathologically. However there was no detectable loss of GCC neurons in NEAMD.

In our study, we aimed to evaluate GCC thickness in NEAMD. In order to find out if there is a cell degeneration at inner layers of retina, associated to that outer layers.

\section{Materials and methods}

\section{Participants and patient groups}

This retrospective, comparative study was approved by the Ethical Review Committee of Ufuk University and adhered to the provisions of the Declaration of Helsinki for research involving human subjects. The medical records of 28 patients diagnosed with NEAMD who suffered from early or intermediate AMD (drusen group) with mild retinal pigment epithelial abnormalities but without other pathology (eg, geographic atrophy, pigment epithelial detachment) and 28 age-matched control eyes were enrolled.Informed consent form was taken from all patient.

All eyes underwent full ophthalmic evaluation including best-corrected visual acuity (BCVA) test, slit lamp examination, and fundus examination. Cases with cataract and media opacity which prevent SD-OCT image, retinal edema, and serous detachment, pigmentary epithelial detachment in SD-OCT, glaucoma, sferic equivalant $>6 \mathrm{D}$ were excluded.

After detailed ophthalmic examination macular scans were taken with spectral domain optical coherence tomography (Cirrus; Carl Zeiss Meditec, Dublin, CA, USA). GCC thickness (the retinal ganglion cell layer and inner plexiform layer) was measured automatically as average, minimum, temporal superior, superior, nasal superior, nasal inferior, inferior, and temporal-inferior segments by SD-OCT and results were compared between groups.

\section{$S D-O C T$}

Imaging was obtained using an SD-OCT device (Cirrus; Carl Zeiss Meditec). Macular scan (macular cube $512 \times 218$ ) was performed through dilated pupil with the SD-OCT. The GCC analysis algorithm was used to automatically measure the macular GCA thickness. ${ }^{10}$ Software version 6.0 of the GCA algorithm (Carl Zeiss Meditec) was used to process the data and detects and measures macular GCIPL thickness within a $6 \times 6 \times 2 \mathrm{~mm}$ cube centered on the fovea. The following macular GCIPL thickness measurements were analyzed: average, minimum, and sectoral (superonasal, superior, superotemporal, inferotemporal, inferior, and inferonasal). ${ }^{11,12}$

In SD-OCT technology, the light from the reference arm interferes with the light reflected back from the different layers of the retina, generating spectral interference fringes. This fringe pattern is processed by a high-speed spectrometer, and then undergoes transformation to create a reflectivity profile in depth. Two-dimensional cross-sectional retinal images consisting of 512 A-lines with axial resolutions of $10 \mathrm{~mm}$ can be obtained in $1.28 \mathrm{~s}$. For GCC measurement scan was centered $1 \mathrm{~mm}$ temporal to the fovea. It covers $7 \times 7 \mathrm{~mm}$ area of the central macula. ${ }^{4}$ GCC thickness parameters indicate the retinal ganglion cell layer and inner plexiform layer in the area above the horizontal meridian. The software analyzes the values, compares them with the device's internal normative database, and generates a color-coded significance map. An instrument provided classification is indicated in a color-coded manner: sectors classified as 'within normal limits' $(P>5 \%)$ are printed in green, sectors classified as 'borderline' $(P<5 \%$ but $>1 \%)$ in yellow, and sectors classified as 'outside normal limits' $(P<1 \%)$ in red.

\section{Statistics}

The SPSS 21.0 program package was used for statistical analysis. Normal distribution fitting was checked with Kolmogorov-Smirnov test. Mann-Whitney $U$-test was used to compare the measured ganglion cell layer parameter values between the healthy controls and AMD group, respectively. The Pearson $\chi^{2}$ test was used to evaluate retinal pigment epithelial abnormalities and systemic disease between two groups. $P$-values of 0.05 or lower were considered to indicate statistical significance.

\section{Results}

One hundred one eyes of 56 participating were examined, retrospectively. Eight of the 28 patients were men and 20 were woman in patient group and 11 of the 28 patients were men and 17 were woman in control group. The mean $( \pm S D)$ age was $68.7 \pm 8.73$ years in patient group and $61.51 \pm 5.66$ years in control group. There were no significant difference between the groups for age, gender distribution, intraocular pressure, and refraction $(P>0.05)$. 
We compared the BCVA between two groups. The mean $( \pm \mathrm{SD})$ BCVA of the participants's eye were $0.78 \pm 0.26$ in patient group and $0.97 \pm 0.11$ in control group. BCVA was also significantly better in control group than patient group $(P<0.01$, Mann-Whitney $U$-test). This was an absolutely expected result. Because, retinal damage in patient with NEAMD results with varying degrees of decrease in visual acuity. The demographic and ophthalmic examination data of the participants are shown in Table 1.

Eight of the 28 patients had hypertension in patient group, 3 of the 28 patients had diabetes mellitus, and 6 of the 28 patients had hypertension and diabetes mellitus together. On the other hand, 10 of the 28 patients had hypertension, 3 of the 28 patients had diabetes mellitus, and 7 of the 28 patients had hypertension and diabetes mellitus together in control group. There was no significant correlation between systemic diseases and GCC thickness between groups (Mann-Whitney $U$-test, $P>0.05)$.

GCC thickness were average $71.53 \pm 16.53 \mu \mathrm{m}$, minimum $62.36 \pm 21.51 \mu \mathrm{m}$, temporal superior $72.23 \pm 14.60 \mu \mathrm{m}$, superior $72.76 \pm 20.40 \mu \mathrm{m}$, nasal superior $72.31 \pm 20.13 \mu \mathrm{m}$, nasal inferior $69.74 \pm 20.51 \mu \mathrm{m}$, inferior $69.38 \pm 19.03 \mu \mathrm{m}$ and temporal-inferior $73.12 \pm 15.44 \mu \mathrm{m}$ in patient group. And the corresponding values in control group were average $81.46 \pm 4.90 \mu \mathrm{m}$, minimum $78.66 \pm 6.00 \mu \mathrm{m}$, temporal superior $81.51 \pm 4.66 \mu \mathrm{m}$, superior $82.94 \pm 5.14 \mu \mathrm{m}$, nasal superior $81.79 \pm 5.86 \mu \mathrm{m}$, nasal inferior $80.94 \pm 6.18 \mu \mathrm{m}$, inferior $80.14 \pm 6.30 \mu \mathrm{m}$ and temporal-inferior $81.75 \pm 5.26 \mu \mathrm{m}$. There was significant differences between two groups in each segments (Mann-Whitney $U$-test, $P<0.05$ ). The GCC thickness examination data of the participants are shown in Table 2, Figure 1.

\section{Discussion}

Visual information generated by the photoreceptor cells is transmitted to the brain by the retina ganglion cells (RGCs) which are located in the innermost layer of the retina.

Table 1 Participants demographic and ophthalmic examination data

\begin{tabular}{lcc}
\hline & Drusen (1) & Control (2) \\
\hline Participants $(n)$ & 28 & 28 \\
Age, years (mean \pm SD) & $68.7 \pm 8.73$ & $61.51 \pm 5.66$ \\
Sex (male/female) & $8 / 20$ & $11 / 17$ \\
BCVA (mean \pm SD) & $0.78 \pm 0.26$ & $0.97 \pm 0.11$ \\
Hypertension & 8 & 10 \\
Diabetes mellitus & 3 & 3 \\
Hypertension and diabetes mellitus & 6 & 7 \\
\hline
\end{tabular}

RGCs are usually a single layer in the peripheral retina; but within the macula, they are multilayered and the fovea centralis has the greatest density of ganglion cells. ${ }^{13,14}$

GCC are affected by multiple diseases such as glaucoma and macular degenerations which caused structural changes in the retina and choroid. Tan et al, ${ }^{13}$ reported that retinal nerve fiber layer and ganglion cell thickness were significantly lower than normal group in glaucoma patient. This result has showed that ganglion cell layer thickness measurement was important for glaucoma diagnosis.

AMD is one of the leading cause of irreversible vision loss and blindness among elderly persons. ${ }^{1,2}$ In AMD patients with severe photoreceptor loss, decreased input to the inner retina may result in transneuronal degeneration. Acellular deposits of lipids, proteins, and inflammatory mediators, which is called drusen, are common both early and late stages of disease.

AMD may potentially affect macular thickness measurement by effectively the outer retinal layers, but

Table 2 Participants GCL+IPL thickness examination data

\begin{tabular}{lccc}
\hline $\begin{array}{l}\text { Ganglion cell analysis } \\
\text { parameters }(G C L+I P L) \\
(\mu m, \text { mean } \pm S D)\end{array}$ & $\begin{array}{c}\text { Drusen } \\
(1 ; \mathrm{n}=28)\end{array}$ & $\begin{array}{c}\text { Control } \\
(2 ; \mathrm{n}=28)\end{array}$ & P-value \\
\hline Average thickness & $71.53 \pm 16.53$ & $81.46 \pm 4.90$ & $0.001^{\mathrm{a}}$ \\
Minimum thickness & $62.36 \pm 21.51$ & $78.66 \pm 6.00$ & $0.000^{\mathrm{a}}$ \\
Temporal superior thickness & $72.23 \pm 14.60$ & $81.51 \pm 4.66$ & $0.000^{\mathrm{a}}$ \\
Superior thickness & $72.76 \pm 20.40$ & $82.94 \pm 5.14$ & $0.001^{\mathrm{a}}$ \\
Nasal-superior thickness & $72.31 \pm 20.13$ & $81.79 \pm 5.86$ & $0.032^{\mathrm{a}}$ \\
Nasal-inferior thickness & $69.74 \pm 20.51$ & $80.94 \pm 6.18$ & $0.016^{\mathrm{a}}$ \\
Inferior thickness & $69.38 \pm 19.03$ & $80.14 \pm 6.30$ & $0.005^{\mathrm{a}}$ \\
Temporal-inferior thickness & $73.12 \pm 15.44$ & $81.75 \pm 5.26$ & $0.001^{\mathrm{a}}$ \\
\hline
\end{tabular}

Abbreviations: GCL, ganglion cell layer; IPL, inner plexiform layer.

${ }^{a}$ Mann-Whitney Test.

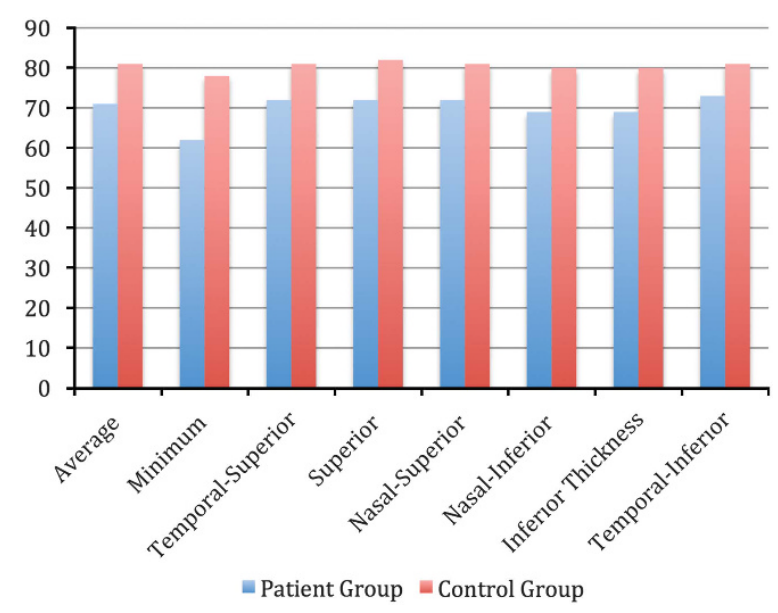

Figure 1 Participants GCL+IPL thickness examination data. 
there is no available literature that investigated ganglion cell complex thickness with the SD-OCT in this patient group. ${ }^{13,15}$

In a study, which was performed histopathological manner in AMD donors, GCL and photoreceptor topography was measured and GCL neurons survival level and relationship between photoreceptor loss was examined in the same eyes. These study findings were $47 \%$ loss of GCL neurons in end-stage cases of exudative AMD (EAMD) but preservation of GCL neurons in NEAMD. ${ }^{13}$ Conversely, our study resulted in a reduction in ganglion cell layer in NEAMD. But there is no any other study to support it. In a study of Chauhan et al, 16 which was measured retinal bands in the OCT images and compared with measurements of retinal layers on histology, reported that the most significant factor affecting reproducibility was the variation in polarization setting and the primary interface component also exist in the images of retina in vivo. Consideration of the differences in results, may cause a misleading view.

Ganglion cell layer which are directly influenced by glaucomatous ganglion cell loss and other macular degeneration like RP. Similar to EAMD eyes, RP eyes exhibits $50-75 \%$ GCL preservation and a positive correlation between levels of photoreceptor and GCL neuron loss in RP. More macular GCL neurons remained in the eyes with AMD than in the eyes with RP. This difference between AMD and RP results could be owing to noncomparable disease stages or differences in disease course. ${ }^{17-19}$

Systemic diseases like diabetes and hypertension, which frequently cause retinopathies leading to blindness effect the morphology of RGC. The axons in diabetic and hypertensive retinopathy retinas showed morphologic changes such as irregular swelling and beading. Dendritic field sizes were significantly reduced in RGC of both hypertensive and diabetic retinas. ${ }^{20}$ Our findings also showed that there was no significant correlation between GCC thickness and hypertension and diabetes.

Several studies had found increasing age is associated with thinner GCC layer, in our study there was no statistically significant correlation between the age and GCC layer in both groups. ${ }^{21-23}$ As our study groups include presbiyopic and AMD patients, our age range is narrow, so it is possible no to be found a difference between the age and ganglion cell layer thickness.

Finally, our results show that ganglion cells have been affected and GCC thickness decreases in NEAMD. Therefore, it can be suggested that ganglion cells may decrease more in advanced AMD, so it should be considered in patients whose visual acuity did not improve despite aggressive treatment. Future studies need to be directed toward further understanding of the effect of AMD on ganglion cell layer.

\section{Summary}

\section{What was known before}

- AMD is a degenerative and progression disease that affects bruch membrane, retinal pigment epithelium, and choriocapillaris. And there is no literature about ganglion cell thickness in AMD.

\section{What this study adds}

- Our results show that ganglion cells have been affected and GCC thickness decreases in NEAMD. Therefore, it can be suggested that ganglion cells may decrease more in advanced AMD, so it should be considered in patients whose visual acuity did not improve despite aggressive treatment. So this is the first publish about this issue.

\section{Conflict of interest}

The authors declare no conflict of interest.

\section{References}

1 Brucker JA. Age-related macular degeneration. Retina 2009; 29: S2-S4.

2 Yang KE, Wang FH, Liang YB, Wong TY, Wang JJ, Zhan SY et al. Association between cardiovascular risk factors and early age-related macular degeneration in a rural chinese adult population. Retina 2014; 34(8): 1539-1553.

3 Bird AC, Bressler NM, Bressler SB, Chisholm IH, Coscas G, Davis MD et al. An international classification and grading system for age-related maculopathy and age- related macular degeneration. Surv Ophthalmol 1995; 39: 367-374.

4 Medeiros NE, Curcio AC. Preservation of ganglion cell layer neurons in age-related macular degeneration. Invest Ophtalmol Vis Sci 2001; 42: 795-803.

5 Jager RD, Mieler WF, Miller JW. Age-related macular degeneration. N Engl J Med 2008; 358: 2602-2617.

6 Yi K, Mujat M, Park BH, Sun W, Miller JW, Seddon JM et al. Spectral domain optical coherence tomography for quantitative evaluation of drusen and association structural changes in non-neovascular age-related macular degeneration. Br J Ophthalmol 2009; 93: 176-181.

7 Garas A, Papp A, Hollo G. Influence of age-related macular degeneration on macular thickness measurement made with fourier-domain optical coherence tomography. J Glaucoma 2013; 22: 195-200.

8 Koh VT, Tham YC, Cheung YC, Wong WL, Baskaran M, Saw SM et al. Determinants of ganglion cell-inner plexiform layer thickness measured by high-definition optical coherence tomograph. Invest Ophthalmol Vis Sci 2012; 53: 5853-5859.

9 Wang M, Hood DC, Cho JS, Ghadiali Q, De Moraes CG, Zhang $\mathrm{X}$ et al. Measurement of local retinal ganglion cell layer thickness in patients with glaucoma using frequencydomain optical coherence tomography. Arch Ophthalmol 2009; 127: 875-881.

10 Sato S, Hirooka K, Baba T, Tenkumo K, Nitta E, Shiraga F. Correlation between the ganglion cell-inner plexiform layer thickness measured with cirrus HD-OCT and macular visual field sensitivity measured with microperimetry. Invest Ophthalmol Vis Sci 2013; 54: 3046-3051. 
11 Mwanza JC, Oakley JD, Budenz DL, Chang RT, Knight OJ, Feuer WJ. Macular ganglion cell-inner plexiform layer: automated detection and thickness reproducibility with spectral domain-optical coherence tomography in glaucoma. Invest Ophthalmol Vis Sci 2011; 52: 8323-8329.

12 DeBuc DC, Somfai GM, Ranganathan S, Tatrai E, Ferencz M, Puliafito CA. Reliability and reproducibility of macular segmentation using a custom-built optical coherence tomography retinal image analysis software. J Biomed Opt 2009; 14: 064023.

13 Tan O, Chopra V, Lu AT, Schuman JS, Ishikawa H, Wollstein $\mathrm{G}$ et al. Detection of macular ganglion cell loss in glaucoma by Fourier-domain optical coherence tomography. Ophthalmology 2009; 116: 2305-2314.

14 Seong M, Sung KR, Choi EH, Kang SY, Cho JW, Um TW et al. Macular and peripapillary retinal nerve fiber layer measurements by spectral domain optical coherence tomography in normal-tension glaucoma. Invest Ophthalmol Vis Sci 2009; 51: 1446-1452.

15 Garas A, Vargha P, Hollo G. Reproducibility of retinal nerve fibre layer and macular thickness measurement with RTVue100 optical coherence tomography. Opthalmology 2010; 117: 738-746.

16 Chauhan DS, Marshall J. The interpretation of optical coherence tomography images of the retina. Invest Ophthalmol Vis Sci 1999; 40: 2332-2342.
17 Stone JL, Barlow WE, Humayun MS, de Juan E Jr, Milam $\mathrm{AH}$. Morphometric analysis of macular photoreceptors and ganglion cells in retinas with retinitis pigmentosa. Arch Ophthalmol 1992; 110: 1634-1639.

18 Santos A, Humayun M, de Juan E Jr. Preservation of the inner retina in retinitis pigmentosa: a morphometric analysis. Arch Ophthalmol 1997; 115: 511-515.

19 Heckenlively JR. Retinitis Pigmentosa. JB Lippincott: Philadelphia, 1988.

20 Ishikawa H, Stein DM, Wollstein G, Beaton S, Fujimoto JG, Schuman JS. Macular segmentation with optical coherence tomography. Invest Ophthalmol Vis Sci 2005; 46: 2012-2017.

21 Meyer-Rüsenberg B, Pavlidis M, Stupp T, Thanos S. Pathological changes in human retinal ganglion cells associated with diabetic and hypertensive retinopathy. Graefes Arch Clin Exp Ophthalmol 2007; 245(7): 1009-1018.

22 Klaver CC, Wolfs RC, Vingerling JR, Hofman A, de Jong PT. Age-spesific prevalence and causes of blindness and visual impairment in an older population: the Rotterdam Study. Arch Ophthalmol 1998; 116: 653-658.

23 Gao H, Hollyfield JG. Aging of the human retina: differential loss of neurons and retinal pigment epithelial cells. Invest Ophthalmol Vis Sci 1992; 33: 1-17.

24 Harman A, Abrahams B, Moore S, Hoskins R. Neuronal density in the human retinal ganglion cell layer from 16-77 Years. Anat Rec 2000; 260: 124-131. 